\title{
SCREENING TEST TO DETECT RECENT TOXOPLASMA GONDII INFECTIONS IN PREGNANT WOMEN
}

\section{By}

ANWAR HOSAINY ABO HASHIM ${ }^{1}$ and AFAF ABDEL-GHANY ATTYA ${ }^{2}$

Department of Parasitology, Faculty of Medicine, Al Azhar University, Nasr City ${ }^{1}$, and Department of Gynecology and Obstetrics, New Cairo Hospital, Ministry of Health and Populations ${ }^{2}$, Egypt (Correspondence: anwarhosainy@yahoo.com).

\begin{abstract}
The differentiation between acute and latent forms of Toxoplasma gondii (T. gondii) infection is still considered as a complicated issue. This study elucidated the establishment of a method that can detect most, if not all, of the recent infections with $T$. gondii through detecting both the immunological and genetic markers. The study included cases' group (G1): 30 pregnant women considered to be a high-risk group (with history of abnormal pregnancy outcomes), and the controls $(\mathrm{G} 2)$ were 20 apparently healthy women cross matched in ages but with a history of normal pregnancy. The two groups were subjected to PCR and immunoblotting in the diagnosis of $T$. gondii infection compared to the routinely used assays (Rapid toxo IgM by immunochromatography \& ELISA IgM).

The results showed that of 30 pregnant women (G1) 3(10\%) were positive by Rapid ToxoIgM, 5(16.67\%) by ELISA-IgM, 9(30\%) by immunoblotting and 6(20\%) by PCR.
\end{abstract}

Key words: Pregnant women, PCR, ELISA, Immunoblotting, Rapid-Toxo-IgM.

\section{Introduction}

Primary infections with $T$. gondii acquired during pregnancy are usually asymptomatic for the pregnant woman but can lead to serious neonatal complications (Linguissi, 2012). In countries such as the United States (Li et al, 2000) testing for antibodies toToxoplasma in pregnancy is performed only in suspected cases. The first serum sample is usually taken at the first antenatal health care visit confirming pregnancy. The test to be used in such an antenatal screening should ideally be able to determine if the infection occurred after conception. Antenatal serological screening of $T$. gondii infection based on $\operatorname{IgG}$ and $\operatorname{IgM}$ detection is the mainstay in monitoring the risk for the congenital toxoplasmosis.

Among the serological tests, the indirect haemagglutination (IHA) proved to be more or less sensitive and more labor intensive (Malhotra et al, 1991). Indirect fluorescent antibody (IFA) test gave false-positive results with the rheumatoid factor, and the Sabin-Feldman dye test titres did not correlate with the severity of the toxoplasmosis illness (McCabe and Remington, 1983). Enzyme-linked immunosorbent assay (ELISA) (both conventional and avidity) can be used for diagnosis and prognosis. ELISA has the sensitivity of about $88 \%$, with a range of 83.3-98.6\% and is $97 \%$ specific for clinching a diagnosis of toxoplasmosis. (Gamble et al, 2005). Routine serologic diagnosis of toxoplasmosis provides high sensitivity, but specificity varies depending on the test used, and false-positive $\operatorname{IgM}$ antibody test results have been reported by other investigators (Wilson et al, 1997). In addition, even true positive results must be interpreted with caution (Liesenfeld et al, 1997) because IgM antibodies may persist for 1 year after acute infection (Francis and Joynson, 1993).

Diagnosis of primary infection with $T$. gondii in early pregnancy can be improved by determination of anti-toxoplasma IgG avidity, which has the ability to discriminate between recent and prior infections (Pelloux et al, 1998). The high sensitivity, combined with the high specificity, offered by the PCR led us to investigate the presence of the $T$. gondii genome in maternal blood in cases of pregnancy where infections with this parasite were suspected. Previous studies confirmed that the PCR could actually detect $T$. gondii in blood specimens of women before 
or during pregnancy (Hussein et al, 2002). The clearance time for Toxoplasma DNA from the blood of patients with acute toxoplasmic lymphadenopathy was estimated to be during 5.5-13 weeks. Based on this, the presence of Toxoplasma DNA in the maternal blood most probably indicates a recent infection or an indicator of apparent parasitemia, which is likely to be clinically significant. However, a negative PCR result does not exclude recent infections because the sensitivity of the PCR, in which a single trophozoite can be detected in a clinical sample, has potential problems for some types of specimens, (Guy and Joynson, 1995) and because the exact kinetics of parasitemia in infected people are not well known. The short duration of parasitemia, or if the numbers of trophozoites circulating in peripheral blood are low, could lead to a sampling error that will produce falsenegative results in such cases. The sensitivity of the PCR was found to be significantly higher for maternal infections that occurred between 17 and 21 weeks gestation $(P<0.02)$ when the amniotic fluid was tested (Romand et al, 2001) If the same applies to blood samples.

Serodiagnosis of recent infection in early pregnancy could be confirmed by PCR result in blood samples collected in the first half of pregnancy, due to the lack of sequential follow-up during pregnancy (Nimr et al, 2004). Immunoblotting (IB) was recommended in congenital toxoplasmosis by threeIgM-band association at 75, 90, \& $100 \mathrm{kDa}$ called the IgM triplet increases the sensitivity to $95.8 \%$ when combined with prenatal and serological neonatal tests (L'Ollivier et $a l, 2012)$. Sarkari et al. (2014) reported that anti $T$. gondii antibodies were detected in sera of 286/1,480 blood donors corresponding to an overall seroprevalence of $19.3 \%$ in this population by enzyme immunoassay. From these, 182 (12.3\%) were seropositive only for IgG, $81(5.47 \%)$ were seropositive only for IgM and 23 (1.6\%) were positive for both IgG and IgM. PCR detected active parasitemia in two (1.9\%) of the Igmpositive subjects. these results highlighted that asymptomatic blood donors, especially those with active parasitemia, may constitute a significant risk of transmitting toxoplasmosis to susceptible recipients.

This is in contrary Zainodini et al. (2014) found that Out of 235 serum samples, 80 $(34.04 \%)$ and $4(1.71 \%)$ were positive regarding anti- $T$. gondii IgG and IgM antibodies, respectively, Real-Time PCR results showed that 14 out of $200(6.97 \%)$ of blood donor had mRNA molecules of SAG1 gene. So evaluation of antibodies could not be reliable, because several donors negative for anti-T. gondii IgM antibodies had detectable SAG1 mRNA molecules. Hence, it seems that molecular diagnostic tests are essential to detect acute infections.

The present study aimed to evaluate the recent infections with $T$. gondii, by using PCR and immunoblotting as compared with the routinely used assays.

\section{Material and Methods}

This case control study was carried out from December 2010 and November 2013. Cases (G1) and controls (G2) were selected from patients attending at Obstetrics and Gynecology clinics, Al Hussein Hospital, Al- Azhar University. Two blood samples were collected from 50 eligible mothers selected based on their history of pregnancy. The cases' group included 30 pregnant women considered to be a high-risk group (with history of abnormal pregnancy outcomes, possible exposure to sources of Toxoplasma, previous screening revealing probable acquisition of Toxoplasma gondii). The controls were 20 apparently healthy women matched for age of the cases but with a history of normal pregnancy. All the cases and controls were subjected to the following.

1- Clinical evaluation all were clinical examined for toxoplasmosis manifestations.

2- Laboratory tests were done for all: Complete blood count (CBC) by using Coulter counter, Bilirubin (BIL) total and direct and $\mathrm{C}$ - reactive protein (CRP). 
3- Toxoplasma specific IgM antibodies (To$x o$-IgM) using commercial Rapid test: A lateral flow chromatography test where antibody complexes are allowed to move along a membrane strip chromatographically to be captured by the pre-coated recombinant specific antigens.

Toxoplasma specific IgM antibodies (Toxo IgM) by ELISA: Principle of the procedure: Competitive immunoassay. Incubation cycles: $1 \times 30$ minutes. They were measured as prescribed using Bioelisa Toxo-IgM immunocapture kits from (Bio-Kit, SA, Barcelona, Spain)

The blood samples $(2-3 \mathrm{~cm}$ each) were withdrawn aseptically by the vini-puncture into labeled test-tubes with cover (Remington and Desmonts, 1990). The separated non lipemic non haemolysed serum was stored frozen at $\left(-20^{\circ} \mathrm{C}\right)$ until used for estimation of the Toxoplasma specific IgM titers, without addition of any preservative was used to avoid inhibition of the enzyme reaction

Interpretation of the test; Qualitative: Divided sample absorbance by the cut-off value: A ratio absorbance/cut-off $>1.1$ would be considered positive, a ratio absorbance / cutoff $<0.9$ would be considered negative, and a ratio absorbance/cut-off between 0.9 and 1.1 would be considered equivocal (Rigsby et al, 2004)

Toxoplasma specific B1 antigen detection in maternal samples by PCR: Blood samples were withdrawn and then preserved at $-20^{\circ} \mathrm{C}$. Samples were digested with Proteinase K in the supplied lysis solution. The lysate was then mixed with ethanol and loaded onto the purification column, where the DNA binds to the silica membrane. Impurities are effectively removed by washing the column with the prepared wash buffers. Genomic DNA is then eluted under low ionic strength conditions with the Elution Buffer.

DNA Extraction: Qiagen kit for extraction of DNA and Eppendorf centrifuge used during extraction of DNA
DNA amplification by PCR Analysis of products: Qiagen kit for cycling of DNA. Thirty $\mu 1$ of the PCR products were loaded on to $1.5 \%$ agarose gel and a unique band of 195 base pair (bp) was visualized using an ultraviolet transilluminator after ethidium bromide staining.

Negative controls for DNA extraction and for PCR assay, using respectively negative samples and water instead of DNA in the reaction mix, were included with all runs. Positive controls consisting of negative samples 'spiked' with $1 \mu \mathrm{g}$ of $T$. gondii DNA (obtained from Tudor Bilharz institute) for DNA extraction and PCR reaction respectively, were also included.

Western blotting, Principle of test: Toxoplasma gondii antigens have been resolved by electrophoresis into bands and transferred by electro blotting on a nitrocellulose membrane (Western Blot procedure). The antigen bearing membrane has been cut into strips. Each strip is numbered and marked at the top of the upper side with a blue line. When doing a comparative immunological test, it is essential to use adjoining strips. The antigen bands at exactly the same level will allow easy interpretation of the test.

Western Blot-IgM: The strips are incubated with an alkaline phosphatase-anti human IgM conjugate. Specific-IgM anti-T. gondii antibodies, if present in the serum samples would then appear as violet colored bands on the strips.

Statistical analysis: Data was organized, tabulated and statistically analyzed using SPSS software statistical computer package version 13 (SPSS Inc, USA). For qualitative data number and distribution\% were calculated. Chi (X2) square tested significance. P $<0.05$ was for interpretation of tests of significance, considered significant and $\mathrm{P}<$ 0.001 was highly significant.

\section{Results}

The results are shown in tables $(1,2 \& 3)$. 
Table 1: Comparison between G1 and G2 using Rapid Toxo-IgM, ELISA-IgM, Immunoblotting-IgM and PCR

\begin{tabular}{|c|c|c|c|c|c|c|c|}
\hline \multirow[b]{2}{*}{ Groups } & & \multicolumn{3}{|c|}{ Cases (G1) } & \multicolumn{2}{|c|}{ Controls (G2) } & Chi-Square \\
\hline & Total $(n=30)$ & Result & $\%$ & Total $(n=20)$ & $\%$ & $\mathrm{X}^{2}$ & P-value \\
\hline \multirow[t]{2}{*}{ Rapid -IgM } & 27 & Negative & 90.00 & 20 & 100.00 & \multirow{2}{*}{7.216} & \multirow{2}{*}{0.065} \\
\hline & 3 & Positive & 10.00 & 0 & 0.00 & & \\
\hline \multirow[t]{2}{*}{ ELISA-IgM } & 25 & Negative & 83.33 & 20 & 100.00 & \multirow{2}{*}{9.591} & \multirow{2}{*}{$0.022 *$} \\
\hline & 5 & Positive & 16.67 & 0 & 0.00 & & \\
\hline \multirow[t]{2}{*}{ Immunoblotting IgM } & 21 & Negative & 70.00 & 20 & 100.00 & \multirow{2}{*}{17.866} & \multirow{2}{*}{$<0.001 * *$} \\
\hline & 9 & Positive & 30.00 & 0 & 0.00 & & \\
\hline \multirow[t]{2}{*}{ PCR } & 24 & Negative & 80.00 & 20 & 100.00 & \multirow{2}{*}{10.978} & \multirow{2}{*}{$0.012 *$} \\
\hline & 6 & Positive & 20.00 & 0 & 0.00 & & \\
\hline
\end{tabular}

$\mathrm{P}>0.05=$ non-significant, $* \mathrm{P}<0.05=$ significant, ${ }^{* *} \mathrm{P}<0.001=$ high significant. Toxo Rapid IgM test showed non-significant increase in positive G1comparison to G2. In ELISA-IgM, Immunoblotting IgM, and PCR showed significant increase in positive G1 in comparison to G2

Table 2: Immunoblotting with Rapid test, ELISA and PCR assay for IgM

\begin{tabular}{|c|c|c|c|c|c|c|c|c|}
\hline \multirow{2}{*}{ Groups } & \multirow{2}{*}{ Result } & No. & \multicolumn{4}{|c|}{ Immunoblotting IgM } & \multicolumn{2}{|c|}{ Chi-Square } \\
\hline & & 30 & Negative & $\%$ & Positive & $\%$ & $\mathrm{X}^{2}$ & $\mathrm{P}$-value \\
\hline \multirow{2}{*}{$\begin{array}{l}\text { Rapid } \\
\text { IgM }\end{array}$} & Negative & 27 & 21 & 70.0 & 6 & 20.0 & \multirow{2}{*}{4.515} & \multirow{2}{*}{$0.033^{*}$} \\
\hline & Positive & 3 & 0 & 0.0 & 3 & 10.0 & & \\
\hline \multirow{2}{*}{$\begin{array}{l}\text { Elisa } \\
\text { IgM }\end{array}$} & Negative & 25 & 21 & 70.0 & 4 & 13.33 & \multirow{2}{*}{8.670} & \multirow{2}{*}{$0.003^{*}$} \\
\hline & Positive & 5 & 0 & 0.0 & 5 & 16.67 & & \\
\hline \multirow{2}{*}{ PCR } & Negative & 24 & 21 & 70.0 & 3 & 10.0 & \multirow{2}{*}{18.567} & \multirow{2}{*}{$<0.00^{* *}$} \\
\hline & Positive & 6 & 0 & 0.0 & 6 & 20.0 & & \\
\hline
\end{tabular}

Rapid-IgM, ELISA-IgM and PCR with immunoblotting IgM were positive G1 in 3/9; 5/9 and 6/ 9 mothers with positive immunoblotting IgM results

Table 3; Results of the PCR assay with Rapid IgM test and ELISA IgM

\begin{tabular}{|c|c|c|c|c|c|c|c|c|}
\hline \multirow{2}{*}{ Groups } & \multirow{2}{*}{ Result } & No. & \multicolumn{4}{|c|}{ PCR } & \multicolumn{2}{|c|}{ Chi-Square } \\
\hline & & 30 & Negative & $\%$ & Positive & $\%$ & $\mathrm{X}^{2}$ & P-value \\
\hline \multirow{2}{*}{$\begin{array}{l}\text { Rapid } \\
\text { Toxo-IgM }\end{array}$} & Negative & 27 & 23 & 76.67 & 4 & 13.33 & \multirow{2}{*}{1.875} & \multirow{2}{*}{0.170} \\
\hline & Positive & 3 & 1 & 3.33 & 2 & 6.67 & & \\
\hline \multirow{2}{*}{ ELISA-IgM } & Negative & 25 & 23 & 76.67 & 2 & 6.67 & \multirow{2}{*}{11.082} & \multirow{2}{*}{$0.001 * *$} \\
\hline & Positive & 5 & 1 & 3.33 & 4 & 13.33 & & \\
\hline
\end{tabular}

PCR with Rapid Toxo- IgM, and ELISA-IgM were positive G1 2/3 and 4/5 respectively and relation with ELISA Toxo $\operatorname{IgM}(\mathrm{P}>0.05$ non-significant.

\section{Discussion}

In the present study, the 30 pregnant women were considered as high-risk group for acute infection by anti-Toxoplasma IgM immunoglobulins by the routinely used Rapid Toxo-IgM, ELISA-IgM and Immunoblotting-IgM and Toxoplasma specific B1 antigen was detected in maternal samples by PCR.

ELISA has been accepted as a sensitive and specific method for the routine laboratory diagnosis of both acute and chronic Toxoplasma infection in humans. An IgMELISA positive test alone or an increase of IgG concentration in two consecutive IgGELISA tests in a fortnight interval is regarded as an indicative of acute toxoplasmosis and the relevant parasitic stage i.e. tachyzoites.this is correct if compared with rapid card test; not goes with if compared with
Immunoblotting IgM or PCR; as The seroprevalence of Toxoplasma infection were 3/30(10\%) positive by Rapid Toxo-IgM, $5 / 30(16.67 \%)$ by ELISA IgM, 9/30 (30\%) by immunoblotting and 6/30(20\%) lby PCR with highest prevalence detected by Immunoblotting IgM. However, the presence of the persistent anti-Toxoplasma IgM antibodies, any positive IgM-ELISA could not definitely be interpreted as acute infection (Gross et al, 2004; Press et al, 2005). PCR for detecting specific Toxoplasma B1 antigen genetic markers of tachyzoites level in blood samples could overcome the abovementioned problem. Moreover, the positive PCR were significantly higher than ELISA (6/30 positive by PCR vs. 5/30 by ELISA), also PCR detected $4 / 5$ positive cases detected by ELISA, and PCR detected 2/25 nega- 
tive cases by ELISA. False-positive ELISAIgM antibody was reported (Hofgärtner $e t$ al, 1997; Wilson et al, 1997). Also, even true positive results must be interpreted with caution (Liesenfeld et al, 1997), as IgM antibodies might persist for one year after acute infection (Bobic et al, 1991; Francis et al, 1993). Sun et al. (2013) reported that the immunorecognition of three kinds of $\mathrm{T}$. gondii strain and development specific antigens with the same set of sera. Results clearly showed that there were strikingly differences in the recognition of these antigens among the samples. The data further supported the conclusion that there is more genetic diversity among the $T$. gondii isolates in China (Zhou et al, 2009; Dubey et al, 2007) which argue for the necessity of the establishment of a method that can detect most, if not all, of the variant specific antibodies. so in this study Immunoblotting IgM detected more positive cases than other tests.

Generally, toxoplasmosis in women is a real problem not only in Egypt (Saleh et al, 2016), but worldwide as Saudi Arabia (Alanazi, 2013), Jordan (Morsy et al, 1978), Libya (Kassem and Morsy, 1991), Kuwait (Iqbal and Khalid, 2007), England (Eng et al, 1999), USA (Davis et al, 2015) and France (Armengol et al, 2017)

\section{Conclusion}

Undoubtedly, congenital toxoplasmosis is a real health problem. The high sensitivity of the immunoblotting-IgM proved T. gondii in maternal blood of pregnant women where the infections were suspected.

\section{References}

Alanazi, AD, 2013: Determination of seropositivity for Toxoplasma gondii in sheep, goats and camels slaughtered for food and human consumptions in Riyadh municipal abattoirs, Saudi Arabia. J. Egypt. Soc. Parasitol. 43, 3:569-76.

Armengol, C, Cassaing, S, Roques-Malecaze, C, Chauvin, P, Iriart, X, et al, 2017: Time before anti-Toxoplasma IgG seroconversion detection by 7 commercial assays in French pregnant women. Diagn. Microbiol. Infect. Dis. 87, 2: 103-7
Bobic, B, Sibalic, D, Djurkovic, O, 1991: High levels of IgM antibodies specific to Toxoplasma gondii in pregnancy 12 years after primary Toxoplasma infection. Gynecol. Obstet. Invest. 31: 182-4.

Davis, SM, Anderson, BL, Schulkin, J, Jones, K, Vanden Eng, J, et al, 2015: Survey of obstetrician-gynecologists in the United States about toxoplasmosis: 2012 update. Arch. Gynecol. Obstet. 291, 3:545-55.

Dubey, JP, Zhu, XQ, Sundar, N, Zhang, H, Kwok, OC, et al, 2007: Genetic and biologic characterization of Toxoplasma gondii isolates of cats from China. Vet. Parasitol. 145, 3/4:3526.

Eng, SB, Werker, DH, King, AS, Marion, SA, Bell, A, et al, 1999: Computer-generated dot maps as an epidemiologic tool: investigating an outbreak of toxoplasmosis. Emerg. Infect. Dis. 15, 6:815-9.

Francis JM, Joynson, DHM, 1993: Duration of specific immunoglobulin A antibody following acute toxoplasmosis as determined by enzyme immunoassay and immunosorbent agglutination assay. Eur J. Clin. Microbiol. Infect. Dis. 12: 556-9.

Gamble, HR, Dubey, JP, Lambillotte, DN, 2005: Comparison of a commercial ELISA with the modified agglutination test for detection of Toxoplasma infection in the domestic pig. Vet. Parasitol. 128:177-81.

Gross, U, Holpert, M, Goebel, S, 2004: Impact of stage differentiation on diagnosis of toxoplasmosis. Ann. It Super Sanita 40, 1:65-70.

Guy, EC, Joynson, DHM, 1995: Potential of the polymerase chain reaction in the diagnosis of active Toxoplasma infection by detection of parasite in blood. J. Infect. Dis. 172:319-22.

Hofgärtner, W, Swanzy, S, Bacina, R, Condon, J, Gupta, M, et al, 1997: Detection of immunoglobulin $\mathrm{G}(\mathrm{IgG})$ and $\operatorname{IgM}$ antibodies to Toxoplasma gondii: evaluation of four commercial immunoassay systems. J. Clin. Microbiol. 35:3313-5.

Hussein, AH, Nagaty, IM, Fouad, MA, 2002: Evaluation of IgMELISA versus PCR in diagnosis of recent Toxoplasma gondii infection. J. Egypt. Soc. Parasitol. 32, 2: 639-46.

Kassem, HH, Morsy, TA, 1991: The prevalence of anti-Toxoplasma antibodies among pregnant women in Benghazi, (S.P.L.A.J.) Libya J. Egypt. Soc. Parasitol. 21, 1:69-74. 
Iqbal, J, Khalid, N, 2007: Detection of acute Toxoplasma gondii infection in early pregnancy by IgG avidity and PCR analysis. J. Med. Microbiol. 56, Pt 11:1495-9.

L'Ollivier, C, Wallon, M, Faucher, B, Piarroux, $R$, et al, 2012: Comparison of mother and child antibodies that target high-molecular-mass Toxoplasma gondii antigens by immunoblotting improves neonatal diagnosis of congenital toxoplasmosis. Clin. Vaccine Immunol. 19, 8:13268

Li, S, Maine, G, Suzuki, Y, Araujo, FG, Galvan, G, et al, 2000: Serodiagnosis of recently acquired Toxoplasma gondii infection with a recombinant antigen. J. Clin. Microbiol. 38:17984.

Liesenfeld, O, Press, C, Montoya, JG, Gill, R, Isaac-Renton, JL, et al, 1997: False-positive results in immunoglobulin IgM) Toxoplasma antibody tests and importance of confirmatory testing: the Platelia Toxo IgM test. J. Clin. Microbiol. 35:174-9.

Linguissi, L, 2012: Seroprevalence of toxoplasmosis and rubella in pregnant women attending antenatal private clinic at Ouagadougou, Burkina Faso. Asian Pac. J. Trop. Med. 5, 10:810-13.

Malhotra, VL, Bharadwaj, Y, Lakshmy, A, Kapur, H, Prakash, K, 1991: Comparison of enzyme linked immunosorbent assay and indirect haemagglutination test in serologic diagnosis of toxoplasmosis. J. Commun. Dis. 23:154-6. McCabe, RE, Remington, JS, 1983: The diagnosis and treatment of toxoplasmosis. Eur. J. Clin. Microbiol. 2:95-104.

Morsy, TA, El-Dasoqui, ST, Michael, SA, 1978: Toxoplasmin skin tests in mentally retarded children in Jordan. J. Egypt. Publ. Hlth. Assoc. 53, 1/2:87-90

Nimr, L, Pelloux, H, El-khatib, L, 2004: Detection of Toxoplasma gondii DNA and specific antibodies in high-risk pregnant women Am. J. Trop. Med. Hyg., 71, 6: 831-5

Pelloux, H, Brun, E, Vernet, G, Marcillat, S, Jolivet, $M$, et al, 1998: Determination of antiToxoplasma gondii immunoglobulin G avidity: adaptation to the Vidas system BioMerieux. Diagn. Microbiol. Infect. Dis. 32: 69-73.

Press, C, Montoya, JG, Remington, JS, 2005: Use of a single serum sample for diagnosis of acute toxoplasmosis in pregnant women and other adults. J. Clin. Microbiol. 43, 7:3481-3.
Remington, JS, Desmonts, G, 1990: Toxoplasmosis in: Infectious diseases of the fetus and newborn infant, edited by Remington, J.S. and Klein, J.O., $3^{\text {rd }}$ edition, Saunders Co. Philadelphia.

Rigsby, P, Rijpkema, S, Guy, EC, Francis J, Das, RG, 2004: Evaluation of a candidate international standard preparation for human anti Toxoplasma immunoglobulin G. J Clin Microbiol. 42:5133-8.

Romand, S, Wallon, M, Franck, J, Thulliez, P, Peyron, F, et al, 2001: Prenatal diagnosis using polymerase chain reaction on amniotic fluid for congenital toxoplasmosis. Obstet. Gynecol. 97:296-300.

Saleh, AMA, Al-Agroudi, MA, Morsy, TA, 2016: Occupational, nosocomial or hospital acquired toxoplasmosis. J. Egypt. Soc. Parasitol. 46, 3: 407-18.

Sarkari, B, Shafiei, R, Zare, M, Sohrabpour, S, Kasraian, L, 2014: Seroprevalence and molecular diagnosis of Toxoplasma gondii infection among blood donors in southern Iran J Infect. Dev. Ctries 8, 4:543-7.

Sun, X, Huijun, L, Boyin, J, Zhiguang, C, Shuai, P, et al, 2013: A comparative study of Toxoplasma gondii seroprevalence in three healthy Chinese populations detected using native and recombinant antigens. Parasites Vectors 6:241-8.

Wilson, M, Remington, J, Clavet, C, Varney, G, Press, C, Ware, D, 1997: Evaluation of six commercial kits for the detection of immunoglobulin $\mathrm{M}$ antibodies to Toxoplasma gondii, The FDA Toxoplasmosis Ad Hoc Working Group. J. Clin. Microbiol. 35:3112-5.

Wilson, M, Remington, JS, Clavet, C, Varney, G, Press, C, et al, 1997: Evaluation of six commercial kits for the detection of immunoglobulin $\mathrm{M}$ antibodies to Toxoplasma gondii: The FDA Toxoplasmosis Ad Hoc Working Group. J. Clin. Microbiol. 35:3112-5.

Zainodini, N, Zare-bidaki, M, Abdollahi, SH, Afrooz, M, Ziaali, N, et al, 2014: Molecular and Serological Detection of Acute and Latent Toxoplasmosis Using Real-Time PCR and ELISA Techniques in Blood Donors of Rafsanjan City, Iran, 2013 Iranian J. Parasitol. 9, 3:336-41 Zhou, P, Zhang, H, Lin, RQ, Zhang, DL, Song, HQ, et al, 2009: Genetic characterization of Toxoplasma gondii isolates from China. Parasitol. Int. 58, 2:193-5. 